Revue d'histoire de l'Amérique française

BQS REVUE D.HISTOIRE DE L'AMÉRIQUE FRANÇAISE

\title{
Coopératives et capitalisme
}

\section{Mario Dumais}

Volume 29, numéro 4, mars 1976

URI : https://id.erudit.org/iderudit/303485ar

DOI : https://doi.org/10.7202/303485ar

Aller au sommaire du numéro

\section{Éditeur(s)}

Institut d'histoire de l'Amérique française

\section{ISSN}

0035-2357 (imprimé)

1492-1383 (numérique)

Découvrir la revue

Citer cette note

Dumais, M. (1976). Coopératives et capitalisme. Revue d'histoire de l'Amérique française, 29(4), 555-557. https://doi.org/10.7202/303485ar d'utilisation que vous pouvez consulter en ligne.

https://apropos.erudit.org/fr/usagers/politique-dutilisation/ 


\section{NOTES DE RECHERCHE \\ $-\mathrm{I}-$ \\ COOPÉRATIVES ET CAPITALISME* \\ MARIO DUMAIS \\ Université de Sherbrooke}

L'une des questions qui se pose inévitablement lorsque l'on étudie l'histoire du mouvement coopératif au Québec, est la manière dont on peut situer le mouvement coopératif par rapport au capitalisme et au socialisme.

La réponse la plus souvent apportée à cette question consiste à voir dans le mouvement coopératif une alternative au capitalisme, alternative qui aurait le mérite de permettre le remplacement de ce système sans devoir recourir au socialisme. C'est la théorie de mouvement coopératif comme troisième voie entre le capitalisme et le socialisme. Il s'agit là, me semble-t-il, d'une perspective qui situe sur un même plan des réalités qui sont de genres différents. Alors que le socialisme et le capitalisme sont des modes de production, la formule coopérative est tout simplement une modalité juridique d'organisation de l'entreprise et, tout comme l'entreprise privée ou d'État, elle peut exister aussi bien dans une société où domine le mode de production capitaliste ou socialiste.

Ainsi les coopératives se distinguent des sociétés par action en ce que, au lieu de s'appeler des actionnaires, les propriétaires d'une coopérative s'appellent des membres ou des coopérants. Au lieu de détenir des actions, ils détiennent des parts sociales. Au lieu de retirer des dividendes, qui sont proportionnels au capital investi, ils retirent des ristournes qui sont proportionnelles au volume d'affaires transigées par le membre avec la coopérative. De plus, contrairement à ce qui se passe dans une société par action, advenant la dissolution d'une entreprise coopérative, les membres ne peuvent se répartir entre eux la valeur résiduelle. Lors de l'assemblée des pro-

* Commentaires présentés à l'occasion de l'atelier sur l'histoire des coopératives au Congrès de l'Institut d'histoire de l'Amérique française, en octobre 1975.

RHAF, vol. 29, no 4 (mars 1976) 
priétaires, dans une société par actions, chacun détient autant de votes qu'il possède d'actions, alors que dans une entreprise coopérative s'applique le principe «un homme - un vote».

Mais ces différences font-elles d'une coopérative une entreprise non-capitaliste? Pour répondre à cette question il est nécessaire de définir ce que l'on entend par capitalisme et de voir si cette définition s'applique au fonctionnement d'une entreprise coopérative.

Le capitalisme, c'est un mode de production caractérisé par une relation d'exploitation qui s'établit entre les propriétaires et les travailleurs d'une entreprise. Les propriétaires de l'entreprise capitaliste achètent la force de travail des employés, et ces derniers vendent leur force de travail en échange d'un salaire. Le salaire, qui représente la valeur marchande de la force de travail, ne compense qu'une partie de la valeur nouvelle créée par la force de travail dans la production. L'autre partie est accaparée par les propriétaires de l'entreprise capitaliste et échappe complètement au contrôle des employés C'est en ce sens que l'on parle d'exploitation pour qualifier cette relation.

En est-il autrement dans une entreprise coopérative? Non, puisque ce que l'on convient d'appeler surplus dans une coopérative est finalement, du point de vue de son origine, exactement semblable au profit d'une société par actions. Que les propriétaires choisissent de répartir entre eux ce surplus en proportion du volume d'affaires qu'ils auront transigé avec la coopérative plutôt qu'en fonction du capital qu'ils y ont investi ne change rien à la nature de la relation qu'entretient l'entreprise avec ses employés.

Ce n'est donc pas l'habit juridique qu'on donne à la propriété des moyens de production qui fait qu'une entreprise est capitaliste ou non. Ce n'est pas non plus parce que la propriété est collective, comme dans une coopérative, qu'une entreprise n'est pas capitaliste. Car n'oublions pas que la propriété collective, par le truchement des sociétés par actions, est précisément la forme la plus répandue de la «coopération» entre les capitalistes.

Faut-il conclure de ces remarques qu'il est absolument indifférent à la classe ouvrière que les entreprises capitalistes soient coopératives ou autres? Non, selon nous, car à certaines conditions les entreprises coopératives pourraient retrouver un sens se rapprochant de celui que possédait ce mouvement à son origine, qui, tout comme le syndicalisme, est une création de la classe ouvrière dans le cours de sa résistance au capitalisme naissant. La question est de savoir 
quels intérêts contrôlent les coopératives, et à quelle fin ces intérêts les utilisent.

Raymond Laliberté, dans son étude sur la culture politique du conseil de la coopération ${ }^{1}$, montre qu'une constante de la pensée de cet organisme consiste à condamner d'une part le socialisme et d'autre part les abus du capitalisme, ce qui montre bien dans quel camp se rangent ceux qui ont historiquement dirigé le mouvement coopératif québécois.

Cependant, il n'y a rien de fatal à ce qu'il en soit toujours ainsi. La règle du «un homme - un vote» qui s'applique au sein des assemblées des coopérants constitue la brèche par laquelle pourrait s'amorcer une reconquête populaire du mouvement coopératif. Reste à déterminer ce que serait dans chacun des secteurs où est présent le mouvement coopératif, le contenu concret d'une politique coopérative pro-ouvrière et anti-capitaliste.

1 Raymond-G. Laliberté, La culture politique du Conseil de la coopération du Québec. Dossiers sur les coopératives, no 1 (Collection publiée par la chaîne de coopération du Département d'économique de l'Université de Sherbrooke, 1973), 82. 